\title{
Negative Impact of COVID 19 on Physical, Mental and Socio-Economic Condition among General Patients
}

\author{
Dr. S. M. Ruhul Amin ${ }^{1 *}$, Dr. Abdur Razzaque ${ }^{2}$, Dr. Md. Moniruzzaman Asraf ${ }^{3}$, Dr. Md. Rashadul Kabir ${ }^{4}$
}

${ }_{1}^{1}$ Assistant Professor, Department of Medicine, Shaheed Ziaur Rahman Medical College, Bogura, Bangladesh
${ }^{2}$ Assistant Professor, Department of Medicine, Shaheed Ziaur Rahman Medical College, Bogura, Bangladesh
${ }^{3}$ Assistant Professor, Department of Medicine, Shaheed Ziaur Rahman Medical College, Bogura, Bangladesh
${ }^{4}$ Assistant Professor, Department of Medicine, Shaheed Ziaur Rahman Medical College, Bogura, Bangladesh

DOI: $10.36347 /$ sasjm.2021.v07i05.002

| Received: 12.03.2021 | Accepted: 25.04.2021 | Published: 08.05.2021

*Corresponding author: Dr. S. M. Ruhul Amin

\section{Abstract}

Original Research Article

Covid-19 is the name of a serious pandemics in the current world. Although this disease is responsible for very limited symptoms and complications like severe acute respiratory syndrome, fever, headache, diarrhea, malaise and weakness but its probability of affecting more people is very high. For this reason, its psychological and socio-economic impact demanded more attention of the world community. We have very limited research-based information regarding this issue. The aim of this study was to evaluate the negative impact of Covid 19 on physical, mental and socio-economic condition among general non-Covid patients. This was a prospective survey-based study which was conducted in the Department of Medicine, Shaheed Ziaur Rahman Medical College, Bogura, Bangladesh during the period from July 2020 to December 2020. In total 128 patients with several health problems, physically or virtually attended the OPD of the mentioned hospital were enrolled as the study population. A pre-designed questionnaire was used in patent data collection. All data were processed, analyzed and disseminated by MS Office and SPSS version as per need. In analyzing the negative impact on physical health of participants we observed, $10.94 \%, 8.59 \%, 7.03 \%, 5.47 \%$ and $3.13 \%$ patients were with feeling of physical fatigue, gaining extra body-weight, insomnia, general weakness and having chronic disease respectively. In this current study, in analyzing the negative impact on mental health of participants we observed feeling of suffocation, feeling of exhausted, fear of falling ill and anxiety about future were found as some major negative mental impacts of Covid 19 on the respondents which was among $11.72 \%, 10.94 \%$, $8.59 \%$ and $7.81 \%$ participants respectively. As negative impact on social life of participants due to Covid 19 continuing remote socialization, intolerance to others, random commitment violation and ended social life were found among $8.59 \%, 3.91 \%, 3.13 \%$ and $1.56 \%$ participants respectively. In analyzing the negative impact of Covid 19 on family income of participants we observed, the monthly family income was decreased up to $25 \%, 50 \%, 75 \%$ and even $100 \%$ of $18.75 \%, 10.16 \%, 3.13 \%$ and $1.56 \%$ participants respectively. That means, negative impact like decreasing monthly family income was found among $38.28 \%$ participant. Pandemic of Covid 19 is a new experience to the world community. The physical, mental and socio-economic impact of Covid 19 among several patients as well as general people required more attention now. Government policy makers as well as world leaders should be more conscious about these impacts to find out the proper way to resolve such epidemic situation.

Keywords: Covid 19, Physical, Mental, Socio-economic, Negative impact.

Copyright (C) 2021 The Author(s): This is an open-access article distributed under the terms of the Creative Commons Attribution 4.0 International License (CC BY-NC 4.0) which permits unrestricted use, distribution, and reproduction in any medium for non-commercial use provided the original author and source are credited.

\section{INTRODUCTION}

Covid-19 is the name of a serious pandemics in the current world. Although this disease is responsible for very limited symptoms and complications like severe acute respiratory syndrome, fever, headache, diarrhea, malaise and weakness but its probability of affecting more people is very high. For this reason, its psychological and socio-economic impact demanded more attention of the world community. We have very limited research-based information regarding this issue. Former infectious disease outbreaks have significantly affected individuals' mental health along with the expected physical health outcomes [1]. The novel coronavirus disease (COVID-19) is by far the most concerning outbreak of atypical pneumonia since the far less detrimental 2003 outbreak of severe acute respiratory syndrome (SARS) [2]. The COVID-19 pandemic has been declared an international public health emergency 
by the World Health Organization (WHO) [3]. As of July 1st 2020, the COVID-19 pandemic has infected over ten million people across the world, causing more than 5,00,000 deaths [4]. Experts are still uncertain of the trajectory of the COVID-19 pandemic, the projected number of cases and deaths, or to what extent quarantine measures will disrupt daily life [5]. The unpredictable nature of this situation and uncertainty regarding COVID- 19 can often trigger psychological distress and mental illness, including depression, anxiety, and traumatic stress [5]. A recent survey by the Indian Psychiatric Society shows a twenty percent increase in mental illnesses since the coronavirus outbreak in India [6]. Day by day the Covid situation in Bangladesh is worsening. The government of Bangladesh suspended or closed all educational institutions and both public and private offices on March 16th 2020 in an effort to contain the outbreak of Covid 19. Public gatherings were also banned [7], and travel from countries with high transmission risk, such as China, Iran, and Italy, was suspended [8]. Despite these efforts, COVID-19 has reached all 64 administrative districts in Bangladesh by July 1st 2020, causing over 145,000 cases and 1,874 deaths thus far [9]. High density of population, poor hygiene practices and poor economic conditions make the majority of the Bangladeshi population particularly vulnerable to this virus (Covid 19). Fear of becoming sick, the isolation of lockdown, the financial necessity to work and the inability to avoid venturing out in public for essential items such as food, idle life, irregular daily routine may increase psychiatric problems within the general population. Recent publications suggest mental health during the COVID-19 pandemic is associated with gender, socioeconomic status, occupation, having COVID-19-like symptoms, perceptions of COVID-19 impacts, interpersonal conflicts, social media use, and social support [10]. Older adults and individuals with low incomes are at increased risk for poor mental health [11].

\section{OBJECTIVES}

\section{General Objective}

- To evaluate the negative impact of Covid 19 on physical, mental and socio-economic condition among general non-Covid patients.

\section{Specific Objective}

- To collect data regarding the socio-demographic status of participants.

- To collect data regarding the negative impact of Covid 19 on physical health of participants.

- To collect data regarding the negative impact of Covid 19 on mental health of participants.

- To collect data regarding the negative impact of Covid 19 on social life of participants.

- To collect data regarding the negative impact of Covid 19 on family income of participants.

\section{METHODOLOGY \& MATERIALS}

This was a prospective interview-based study which was conducted in the Department of Medicine, Shaheed Ziaur Rahman Medical College, Bogura, Bangladesh during the period from July 2020 to December 2020. In total 128 patients with several health problems, physically or virtually attended the OPD of the mentioned hospital were enrolled as the study population. Proper written consents were taken from all the participants before collecting data. A predesigned questionnaire containing the data options of metal physical and socio-economic conditions as well as other relative necessary information was used in patent data collection. Only those status of impact directly associated with Covid 19 acknowledged by respondents were considered for this study. All the participants were made aware about deducting the symptoms and presentation usually associated in nonCovid situation. According to the inclusion criteria of this prospective study both male patients of several ages and professions attended the mentioned hospital regarding several health problems were included as the study population. On the other hand, according to the exclusion criteria of this study severely ill patients, cases of surgery, very aged geriatric patients and ICU patients were excluded. Participant's opinions were the basic source of information in this study. All data were processed, analyzed and disseminated by MS Office and SPSS version as per need.

\section{RESULT}

In this study, among total 128 participants $45 \%$ $(n=58)$ were male and the rest $55 \%(n=70)$ were female. So female was dominating in number and the malefemale ratio was 1:1.2. The highest number of participants were from 41-60 years' age group which was $39.84 \%$. Besides this, $10.16 \%, 31.25 \%$ and $18.75 \%$ participants were from $\leq 20,21-40$ and $>60$ years' age groups respectively. In analyzing the family status of the participants according to the monthly income we observed, the highest number of participants were from lower class families which was $46.88 \%$. Besides this, $38.28 \%$ belonged to middle class families and the rest $14.84 \%$ belonged to upper class families. In this study, near about two third responded were found from rural areas whereas the rest one third participants were found from urban communities. In analyzing the negative impact on physical health of participants we observed, $10.94 \%, 8.59 \%, 7.03 \%, 5.47 \%$ and $3.13 \%$ patients were with feeling of physical fatigue, gaining extra bodyweight, insomnia, general weakness and having chronic disease respectively. In this current study, in analyzing the negative impact on mental health of participants we observed feeling of suffocation, feeling of exhausted, fear of falling ill and anxiety about future were found as some major negative mental impacts of Covid 19 on the respondents which was among $11.72 \%, 10.94 \%, 8.59 \%$ and $7.81 \%$ participants respectively. On the other hand, as negative impact on social life of participants due to Covid 19 continuing remote socialization, intolerance to 
others, random commitment violation, and ended social life were found among $8.59 \%, 3.91 \%, 3.13 \%$ and $1.56 \%$ participants respectively. In analyzing the negative impact of Covid 19 on family income of participants we observed, the monthly family income was decreased up to $25 \%, 50 \%, 75 \%$ and even $100 \%$ of $18.75 \%, 10.16 \%, 3.13 \%$ and $1.56 \%$ participants respectively. That means, negative impact like decreasing monthly family income was found among $38.28 \%$ participant.

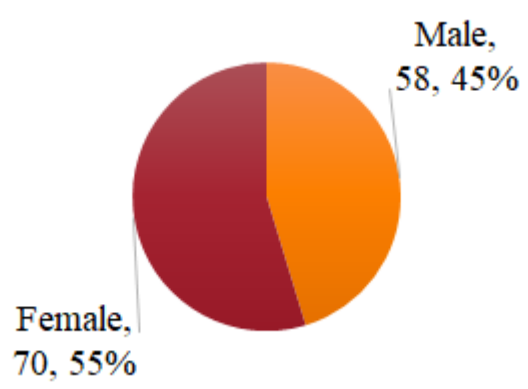

Fig-1: Gender distribution of participants $(n=128)$

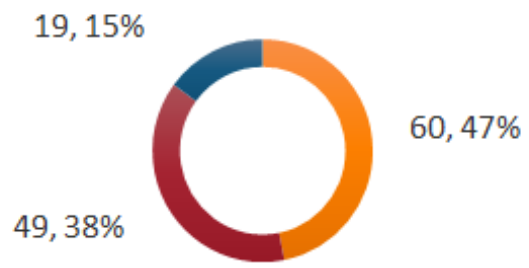

- Lower aiddle a Upper

Fig-2: Family income status of participants $(n=128)$

Table-1: Negative impact on physical health of participants $(n=128)$

\begin{tabular}{|l|l|l|}
\hline Negative impacts & $\mathbf{n}$ & $\mathbf{\%}$ \\
\hline Feeling of physical fatigue & 14 & 10.94 \\
\hline Gaining extra body-weight & 11 & 8.59 \\
\hline Insomnia & 9 & 7.03 \\
\hline General weakness & 7 & 5.47 \\
\hline Having chronic disease & 4 & 3.13 \\
\hline
\end{tabular}

Table-2: Negative impact on mental health of participants $(n=128)$

\begin{tabular}{|l|l|l|}
\hline Negative impacts & $\mathbf{n}$ & $\mathbf{\%}$ \\
\hline Feeling of suffocation & 15 & 11.72 \\
\hline Feeling of exhausted & 14 & 10.94 \\
\hline Fear of falling ill & 11 & 8.59 \\
\hline anxiety about future & 10 & 7.81 \\
\hline Feeling of loneliness & 7 & 5.47 \\
\hline Feeling of sadness & 6 & 4.69 \\
\hline Intolerance to others & 5 & 3.91 \\
\hline Extreme cleaning practices & 3 & 2.34 \\
\hline Feeling of extreme tiredness & 2 & 1.56 \\
\hline
\end{tabular}

Table-3: Negative impact on social life of participants $(n=128)$

\begin{tabular}{|l|l|l|}
\hline Negative impacts & $\mathbf{n}$ & $\mathbf{\%}$ \\
\hline Continuing remote socialization & 11 & 8.59 \\
\hline Intolerance to others & 5 & 3.91 \\
\hline Random commitment violation & 4 & 3.13 \\
\hline Ended social life & 2 & 1.56 \\
\hline
\end{tabular}

Table-4: Negative impact on family income of participants $(n=128)$

\begin{tabular}{|l|l|l|}
\hline Change (Monthly) & n & \% \\
\hline Decreased up to 25\% & 24 & 18.75 \\
\hline Decreased up to 50\% & 13 & 10.16 \\
\hline Decreased up to 75\% & 4 & 3.13 \\
\hline Decreased up to 100\% & 2 & 1.56 \\
\hline Total & 49 & 38.28 \\
\hline
\end{tabular}

\section{DISCUSSION}

The aim of this study was to evaluate the negative impact of Covid 19 on physical, mental and socio-economic condition among general non-Covid patients. Because of the physical health effects of the corona virus and the psycho-social effects of the isolation, quarantine and physical distancing measures adopted, many people have been facing various type of fear (fear to die, to lose the loved ones or to lose the income), many of them struggling with the harsh economic conditions and many people have to survive without the support of their common social networks. Moreover, the current uncertainty in terms of the course of the pandemic can lead to triggering the dysphoric moods. Those challenges also can be elaborated regarding the specific group and their vulnerabilities. In virtue of social isolation, interrupted education, economic stressors of family life, children and adolescents have been facing exacerbated psychological problems and affecting their emotional and mental development. For women and children are facing a vast number of stressors at home, and additionally, increased risk of abuse. Men, on the other hand, are experiencing the deterioration of livelihood opportunities and having the feeling of uncertainty towards the future. As briefed by the UN 2020 [12], there is widespread psychological distress within the communities resulted by the pandemic conditions. In analyzing the negative impact on physical health of participants we observed, $10.94 \%$, $8.59 \%, 7.03 \%, 5.47 \%$ and $3.13 \%$ patients were with feeling of physical fatigue, gaining extra body-weight, insomnia, general weakness and having chronic disease respectively. On the other hand, as negative impact on social life of participants due to Covid 19 continuing remote socialization, intolerance to others, random commitment violation, and ended social life were found among $8.59 \%, 3.91 \%, 3.13 \%$ and $1.56 \%$ participants respectively. To control the spread of this disease, governments of all over the world have taken several measures that have had an enormous impact on the lives of billions of people. Even though physical health is understandably the first priority during a pandemic, the 
impact of the COVID-19 pandemic and of the resulting measures on mental health has also been an important concern [13]. In this current study in analyzing the mental conditions of our respondents, we observed feeling of suffocation, feeling of exhausted, fear of falling ill and anxiety about future were found as some major negative mental impacts of Covid 19 on the respondents which was among $11.72 \%, 10.94 \%, 8.59 \%$ and $7.81 \%$ participants respectively. Past research has indicated that, compared to adults' mental health, young people's mental health is often disproportionately affected by calamities [14]. In addition, social isolation and loneliness precipitate depression and anxiety in children and adolescents [15]. There are three main ways via which the COVID-19 pandemic can affect mental health [13]. First, this pandemic is a long-term, widespread, high-stakes disaster that disrupts daily routines for a long time and creates severe uncertainty about the present and the future. Therefore, the pandemic is a significant source of stress, for adults and youth alike. Second, it is a multisystemic disaster, as it affects and disrupts individuals, families, communities, states, and economies, having long-term effects on the micro-, meso-, and macro-system [16]. Finally, the subjective levels of stress regarding COVID-19 explain part of the debilitating effects of the pandemic on psychological well-being [17]. Third, as Gruber et al., [13] point out, this pandemic disrupts several protective factors for mental health under stress, such as supportive social interactions, access to mental health services, etc. Besides this economic distress is a potential factor of worsening the pandemic situation. In analyzing the negative impact of Covid 19 on family income of participants we observed, the monthly family income was decreased up to $25 \%, 50 \%, 75 \%$ and even $100 \%$ of $18.75 \%, 10.16 \%, 3.13 \%$ and $1.56 \%$ participants respectively. For example, in the current study, fewer than one in five families with financial stress or concerns about having enough food to meet their household basic needs had recently accessed federal benefits or food programs, respectively, warranting further investigation into the ease of access to these services [18]. Furthermore, many of these underlying causes of health inequities will remain after the COVID-19 crisis has subsided [19], suggesting that many of these interventions should be sustained irrespective of the pandemic.

\section{Limitations of the study}

This was a single centered study with a small sized sample. So, the findings of this study may not reflect the exact scenario of the whole country.

\section{CONCLUSION AND RECOMMENDATIONS}

Pandemic of Covid 19 is a new experience to the world community. The physical, mental and socioeconomic impact of Covid 19 among several patients as well as general people required more attention now. Government policy makers as well as world leaders should be more conscious about these impacts to find out the proper way to resolve such epidemic situation. For getting more reliable information we would like to recommend for conducting more studies in several places with larger sized samples.

\section{REFERENCES}

1. Lau JTF, Griffiths S, Choi KC, Tsui HY. Avoidance behaviors and negative psychological responses in the general population in the initial stage of the H1N1 pandemic in Hong Kong. BMC Infect Dis. 2010;10(1):139.

2. Hawryluck L, Gold WL, Robinson S, Pogorski S, Galea S, Styra R. SARS control and psychological effects of quarantine, Toronto, Canada. Emerg Infect Dis. 2004;10(7):1206.

3. WHO. Organization WH (2020) WHO DirectorGeneral's statement on IHR Emergency Committee on Novel Coronavirus (2019-nCoV). 2020. Available at: https ://www.hoint /dg/speec hes/detai 1/who-direc tor-gener al-s-state menton-ihr-emerg ency-commi ttee-on-novel -coron aviru s-(2019- n.

4. WHO. Coronavirus disease (covid-19) update. 2020. Available at: https:// www.who.int/ bangladesh/ emergencies/ https://www.who.int/bangladesh/emergencies/co ro navirus-disease-(covid-19)-update.

5. Zandifar A, Badrfam R. Iranian mental health during the COVID-19 epidemic. Asian J Psychiatr. 2020; 51:101990.

6. Loiwal M. $20 \%$ increase in patients with mental ill-ness since coronavirus outbreak: Survey. India Today. 2020. [Accessec 2020 Jun 30]; India. Available at: https://www.indiatoday.in/india/story/20-percent-increase-in-patients-with-mental-illnesssince- coronavirus-outbreak-survey-16615842020-03-31.

7. WHO. Bangladesh Covid-19 Situation Report No. 4. 2020. Available at:https:// www.who.int/ bangladesh/ emergencies/ coronavirus-disease(covid-19)-update/coronavirus-disease -(covid2019) -bangladesh-situation reports.

8. Anadolu Agency. Bangladesh confirms first case of coronavirus [Internet]. 2020. [accessed 2020 Apr 16]. Available at: https://www.aa.com.tr/en/asiapacific/bangladesh-confirms-first-case-ofcoronavirus-/1758924.

9. IEDCR. Covid-19 Status Bangladesh [Internet]. 2020. [accessed 2020 Apr 16]. Avalable athttps: //www. iedcr.gov.bd/.

10. Mowbray H. In Beijing, coronavirus 2019-nCoV has created a siege mentality. Bmj. 368. Othman N. 2020. Depression, Anxiety, and Stress In The Time of COVID-19 Pandemic In Kurdistan Region, Iraq. Kurdistan J Appl Res, 2020;37-44.

11. Holmes EA, O'Connor RC, Perry VH, Tracey I, Wessely S, Arseneault L, Ballard C, Christensen 
H, Silver RC, Everall I. Multidisciplinary research priorities for the COVID-19 pandemic: a call for action for mental health science. The Lancet Psychiatry. 2020; 7(6):547-560.

12. United Nations Policy Brief, Recommended Actions: COVID-19 and The Need for Action on Mental Health. 2020.

13. Gruber J, Prinstein MJ, Clark LA, Rottenberg J, Abramowitz JS, Albano AM, Aldao A, Borelli JL, Chung T, Davila J, Forbes EE. Mental health and clinical psychological science in the time of COVID-19: Challenges, opportunities, and a call to action. American Psychologist. 2020 Aug 10.

14. Danese A, Smith P, Chitsabesan P, Dubicka B. Child and adolescent mental health amidst emergencies and disasters. The British Journal of Psychiatry, 2020;216(3), 159-162. https://doi.org/10.1192/bjp.2019.244.

15. Loades ME, Chatburn E, Higson-Sweeney N, Reynolds S, Shafran R, Brigden A, Linney C, McManus MN, Borwick C, Crawley E. Rapid systematic review: the impact of social isolation and loneliness on the mental health of children and adolescents in the context of COVID-19. Journal of the American Academy of Child \& Adolescent Psychiatry. 2020 Jun 3. 59(11), 1218-1239.

16. Masten AS. Resilience of children in disasters: A multisystem perspective. International Journal of Psychology, 2020 . https://doi.org/10.1002/ijop.12737.

17. Gotlib IH, Borchers LR, Chahal R, Gifuni AJ, Teresi GI, Ho TC. Early Life Stress Predicts Depressive Symptoms in Adolescents During the COVID-19 Pandemic: The Mediating Role of Perceived Stress. Frontiers in Psychology, 2020;11. https://doi.org/10.3389/fpsyg.2020.603748.

18. Black J. The worst time for food banks to raise barriers to food, 2020. The Province. Available: https://theprovince.com/opinion/ jennifer-blackthe-worst-time-for-food-banks-to-raise-barriersto- food.

19. Eaves S. The housing affordability crisis will still be here after COVID-19, 2020. Generation squeeze. Available: https://www. gensqueeze.ca/housing-after-covid-19. 